\title{
Analysis of plasma jet depositions on a C45 steel used in crankshaft manufacturing
}

\author{
G. MAHU ${ }^{1}$, C. MUNTEANU ${ }^{1},{ }^{*}$, B. ISTRATE ${ }^{1}$, M. BENCHEA $^{1}$ \\ 1"Gheorghe Asachi" Technical University of Iasi, Faculty of Mechanical Engineering, 43 "D. \\ Mangeron" Street, 700050, Iasi, Romania \\ acornelmun@gmail.com
}

Keywords: C45 steel, Plasma coatings, Crankshaft, SEM, XRD, Mechanical properties

\begin{abstract}
Thermal Spray coatings are used in the automotive industry, with multiple applications, offering effective protection solutions in the suspension system, transmission and engine components. Plasma jet deposition may be a solution to classical methods of enhancing wear resistance by chemical or thermochemical treatments in main and crankpin journals. Through this study the deposition of layers on the surface of a C45 steel was analyzed, using the following powders: $\mathrm{Cr}_{3} \mathrm{C}_{2}-\left(\mathrm{Ni}_{20} \mathrm{Cr}\right), \mathrm{Al}_{2} \mathrm{O}_{3}-13 \mathrm{TiO}_{2}, \mathrm{Cr}_{2} \mathrm{O}_{3}-\mathrm{SiO}_{2}-\mathrm{TiO}_{2}$. Powders were deposited with the 9MCE Spraywizard at atmospheric pressure. Microstructural and morphological analyzes were performed by means of optical, electronic and X-ray diffraction microscopy. Microstretch and indentation tests were performed to determine the adhesion of the deposited layer to the base material. As a result of the tests, the layer deposited using the $\mathrm{Al}_{2} \mathrm{O}_{3} 13 \mathrm{TiO}_{2}$ powder has higher hardness characteristics than the layers of $\mathrm{Cr}_{3} \mathrm{C}_{2}-\left(\mathrm{Ni}_{20} \mathrm{Cr}\right)$ and $\mathrm{Cr}_{2} \mathrm{O}_{3}-\mathrm{SiO}_{2}-\mathrm{TiO}_{2}$ powders and that of the base material. This study confirms that plasma jet deposition is an effective solution to classic methods used to increase crankshaft wear resistance, at least in limited production series.
\end{abstract}

\section{Introduction}

To improve the properties of crankshafts, such as wear resistance and increased durability, various heat treatments such as carburizing, nitration, chrome plating, carbonitriding, etc. are applied [1 4]. The plasma jet deposition process is one of the most common thermal spray deposition processes [5]. Studies has been carried out on plasma deposition on the surface of a C45 steel, the most widespread plasma jet deposition method being nitride according to the studies of T.Bell and H.Liu [6, 7]. Plasma jet spraying is an effective method for improving the wear, corrosion, and high temperature resistance of layers deposited on the surface of a material [8]. F. Hakami et al. performed a study on duplex treatment of C45 steel resulting from chromium followed by plasma nitrating; the study found that the resistance of the deposited layer was significantly increased compared to the initial chrome treatment reaching $1540 \mathrm{HV}$ compared to $1270 \mathrm{HV}$ in the case of simple chrome plating $[9,10]$. The purpose of this research is to highlight the characteristics of the layers deposited by the plasma jet spray method on the surface of a C45 steel used in the construction of crankshafts in terms of microstructure, X-ray diffraction, micro scratch test and module Young's. For plasma jet spraying are very important the working parameters. In the case of depositing a layer of $\mathrm{Al}_{2} \mathrm{O}_{3} \mathrm{TiO}_{2}$, nanostructural analysis and tests performed reveal that important changes can occur, so values of layer microhardness may vary from $611 \mathrm{HV}$ to $772 \mathrm{HV}$ in in the case of a current variation from $550 \mathrm{~A}$ to $650 \mathrm{~A}$ [11 - 13].

\section{Experimental}

The steel used in this study has the components in Table 1:

Content from this work may be used under the terms of the Creative Commons Attribution 3.0 license. Any further distribution of this work must maintain attribution to the author(s) and the title of the work, journal citation and DOI. Published under license by Materials Research Forum LLC. 
Table 1. C45 composition.

\begin{tabular}{cccccc}
\hline C45 & C & Si & Mn & S & P \\
\hline$\%$ & 0,45 & 0,17 & 0,52 & 0,031 & 0,032 \\
\hline
\end{tabular}

Using the SPRAYWIZARD 9MCE equipment, produced by Sulzer \& Metco, a plasma jet deposition process was performed using 3 powders: Metco $130-\mathbf{A l}_{2} \mathrm{O}_{3}-\mathbf{1 3 T i O}_{2}$, Metco $\mathbf{8 1 N S}$ $\mathrm{Cr}_{3} \mathrm{C}_{2}-25\left(\mathrm{Ni}_{20} \mathrm{Cr}\right.$ ), Metco $136 \mathrm{~F}-\mathrm{Cr}_{2} \mathrm{O}_{3}-\mathrm{SiO}_{2}-\mathrm{TiO}_{2}$. The powders used for the spraying has the components in Table 2:

Table 2. Powders composition.

Product Chemical composition (nominal wt. \%)

\begin{tabular}{lcccccccc} 
& $\mathrm{TiO}_{2}$ & $\mathrm{Al}_{2} \mathrm{O}_{3}$ & $\mathrm{Cr}_{3} \mathrm{C}_{2}$ & $\mathrm{Ni}$ & $\mathrm{Cr}$ & $\mathrm{Cr}_{2} \mathrm{O}_{3}$ & $\mathrm{SiO}_{2}$ & $\mathrm{TiO}_{2}$ \\
\hline Metco 130 & 13 & 87 & - & - & - & - & - & - \\
Metco 81NS & - & - & 75 & 20 & 5 & - & - & - \\
Metco136F & - & - & - & - & - & 92 & 5 & 3 \\
\hline
\end{tabular}

The spray parameters used for all 3 powders are shown in Table 3.

Table 3. Spray parameters.

\begin{tabular}{cccc} 
Powder & Metco 130 & Metco 81NS & Metco 136F \\
\hline Spray distance, (mm) & 100 & 100 & 100 \\
Injector & 1,8 & 1,8 & 1,8 \\
Curent Intensity, (A) & 600 & 600 & 600 \\
Electric arc voltage (U) & 75 & 75 & 75 \\
Rotation speed (rpm) & 55 & 55 & 55 \\
Argon flow (m3 / h) & 50 & 50 & 50 \\
Hydrogen flow (m3 / h) & 14 & 14 & 14
\end{tabular}

To perform the study, 9 samples were processed, having the dimensions $30 \mathrm{~mm} \mathrm{X} 10 \mathrm{~mm}$ X 2 $\mathrm{mm}$. 
For the study of the microstructure, the samples were prepared metallographically using 200, 500, 800 and 1200 abrasive paper. After preparation, the samples were cleaned with ethyl alcohol and chemically attacked using the $2 \%$ nital reagent.

For the microstructure and samples morphology analysis, the SEM QUANTA 3D Dual Beam microscope, produced by the Dutch FEI, was used. The settings were on the High Vacuum mode using the Large Field Detector (LFG) detector, resulting in magnified 500X, 1000X, and 5000X images with a working distance of about $15 \mathrm{~mm}$.

X-ray diffraction was performed using X-ray diffractometer, X 'Pert Pro MRD, with an X-ray tube with $\mathrm{Cu} \mathrm{k} \alpha, \lambda=1,54 \AA$, using a voltage of $45 \mathrm{KV}$ with an intensity of $40 \mathrm{~mA}$, the diffraction angle ( 2 theta) ranging between 25 and $130^{\circ}$. The adhesion testing of the deposited layers was done by the micro scratch method and the indentation method by means of the CETR UMT-2 tribometer equipped with a DFH-20 Dual Friction / Load Sensor type duralumin, on which a blade whose top has been mounted the radius of $0.4 \mathrm{~mm}$. The indenting speed was $10 \mathrm{~mm} / \mathrm{min}$.

\section{Results and discussion}

Microstructural analysis

In Fig. 1 we can see the SEM images of the layer obtained by spraying the Metco 130 powder. Variations in layer thickness can be seen in Figure 1b.

Values vary in the 279-306 $\mu \mathrm{m}$ range, indicating that the spray had a uniform distribution on the surface of the base material, respecting the manufacturer's spraying specifications. We can see a porous structure with few microcracks ,unmelted compounds and cavities (Figure 1c).

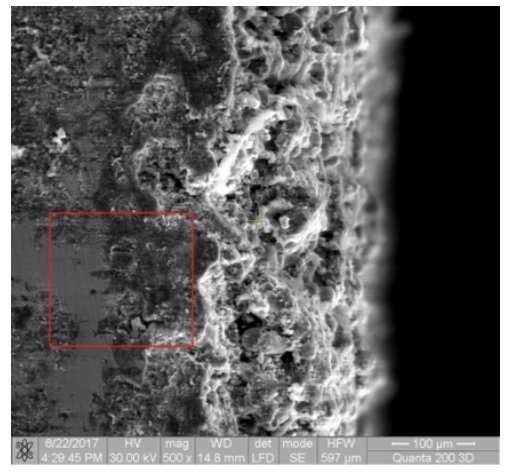

a)

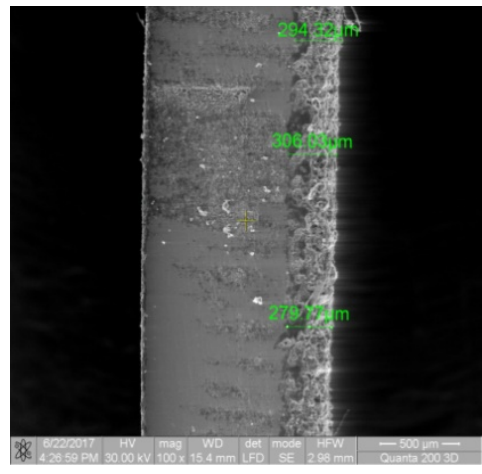

b)

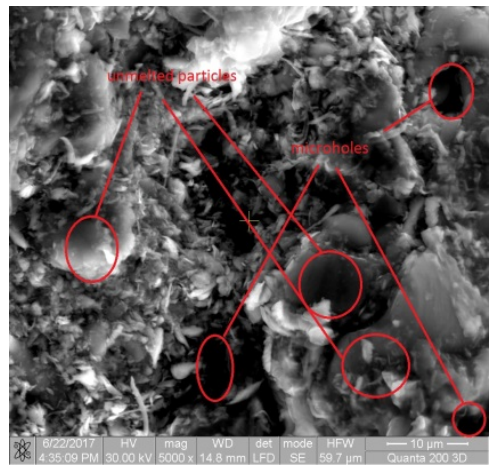

c)

Fig. 1. SEM images of the Metco 130 layer deposited on the surface of the specimens: a) layer separation zone (X5000), b) thickness of the layer (X5000), c) layer structure (X5000).

In Fig. 2a, we can see SEM images in the cross section of the layer obtained after Metco $81 \mathrm{NS}$ spraying. The morphology of the Metco 81NS powder reveals a more compact structure (Figure 2c), with splats without unmelted particles, just with isolated areas with segregated unmelted particles matter and cracks. The thickness of the deposited layer (Fig. 2b) reaching 107 $\mu \mathrm{m}$, being inferior to the Metco 130 powder spray. 


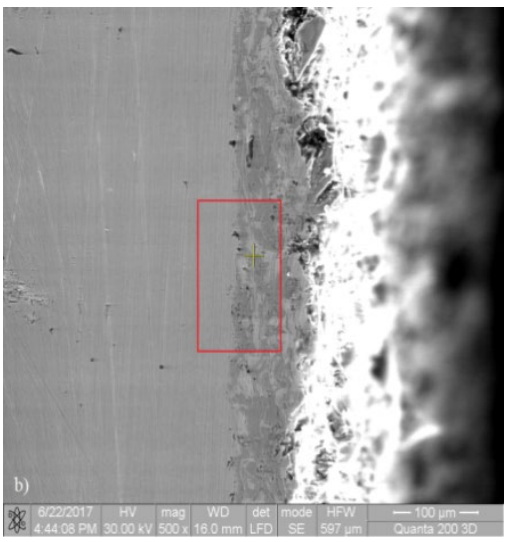

a)

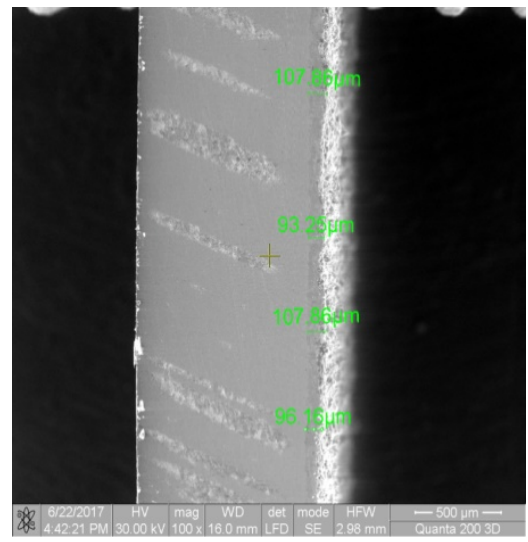

b)

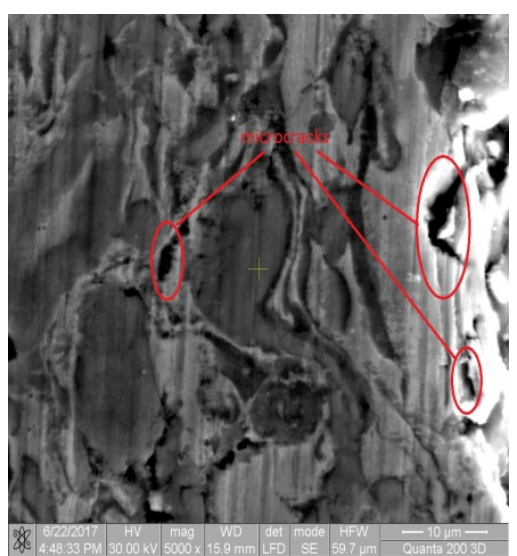

c)

Fig. 2. SEM images of the Metco 81NS layer deposited on the surface of the specimens:

a) layer separation zone (X5000), b) thickness of the layer (X5000), c) structure of the layer (X5000).

The structure obtained from the Metco $136 \mathrm{~F}$ powder spray has a non-uniform accentuated character with few isolated splats and unmelted particles areas segregation, as can be seen from the Fig. 3c. Also high accentuated porosity and isolated microcracks are highlighted. The minimum layer thickness is $96 \mu \mathrm{m}$, reaching maximum values of $110 \mu \mathrm{m}$ (Fig. 3b).

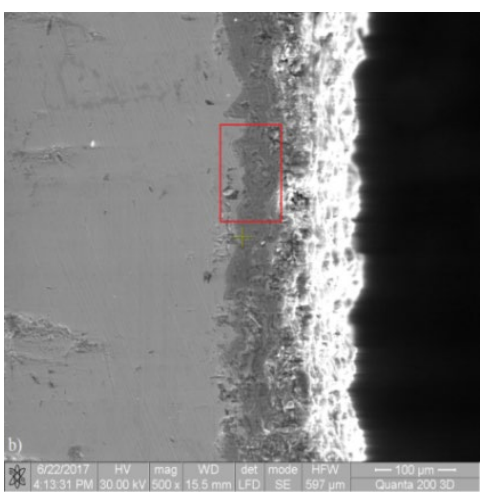

a)

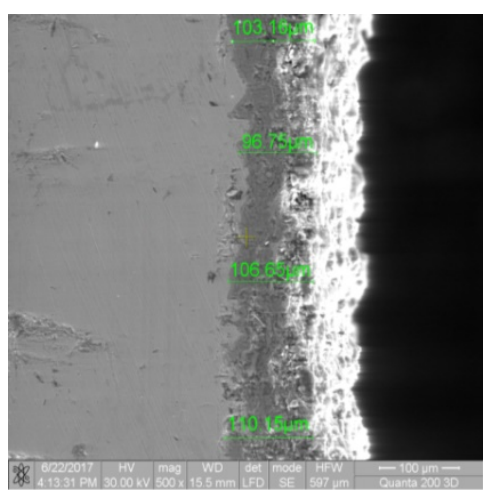

b)

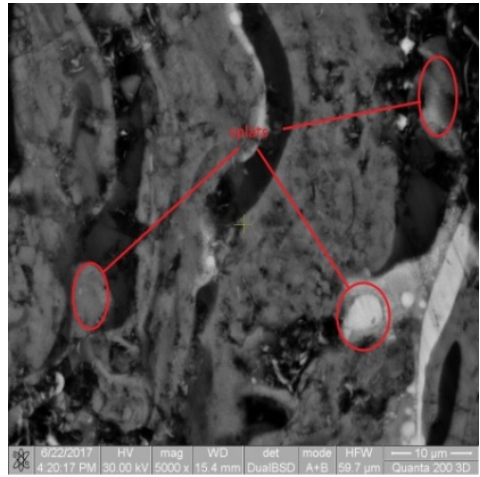

c)

Fig. 3. SEM images of the Metco 136F layer deposited on the surface of the specimens: layer separation zone (X5000), b) layer thickness (X5000), c) layer structure (X5000). 


\section{XRD Analysis}

The predominant phases of the $\mathrm{Al}_{2} \mathrm{O}_{3}$ identified in Fig. 4, for the Metco130 powder, present characteristic peaks at: $25,59^{\circ} ; 35,168^{\circ} ; 43,39^{\circ} ; 57,53^{\circ}$ and $68,28^{\circ} . \mathrm{Al}_{2} \mathrm{O}_{3}$ is identified by a rhombohedral crystalline structure. $\mathrm{TiO}_{2}$ is identified through 2 phases: rutile and anatase, with peaks at: $25,27^{\circ}, 27,47^{\circ}, 36,08^{\circ}, 48,03^{\circ}$ and $54,37^{\circ}$. Rutile and anatase display a tetragonal structure.

Fig. 4b, presents Metco 81NS powder diffraction. Crystalline cubic type structure is revealed for $\mathrm{Cr}$, having peaks at: $44,58^{\circ}, 64,65^{\circ}, 82,31^{\circ}$. The predominant phases of $\mathrm{Cr}_{7} \mathrm{C}_{3}$ powder display peaks at: $39,21^{\circ}, 39,35^{\circ}, 42,58^{\circ}$ and $44,20^{\circ}$. $\mathrm{Cr}_{7} \mathrm{C}_{3}$ powder presents an orthorhombic type crystalline structure. Metco 136F powder's diffraction, shown in figure 4c, has in it's component $\mathrm{Cr}$, displaying a cubic type structure with characteristic peaks at $44,3^{\circ}$ and $81,68^{\circ} . \mathrm{Cr}_{2} \mathrm{O}_{3}$ has peaks at $33,62^{\circ}, 36,23^{\circ}$ and $54,89^{\circ}$.

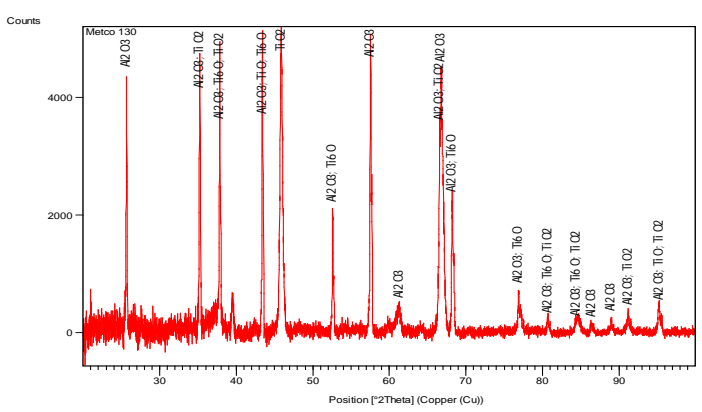

a)

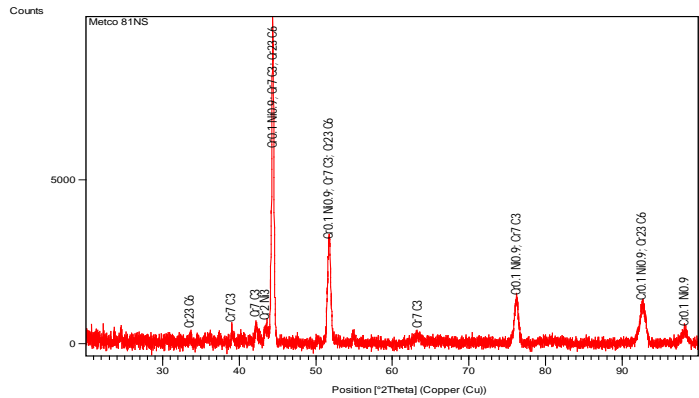

b)

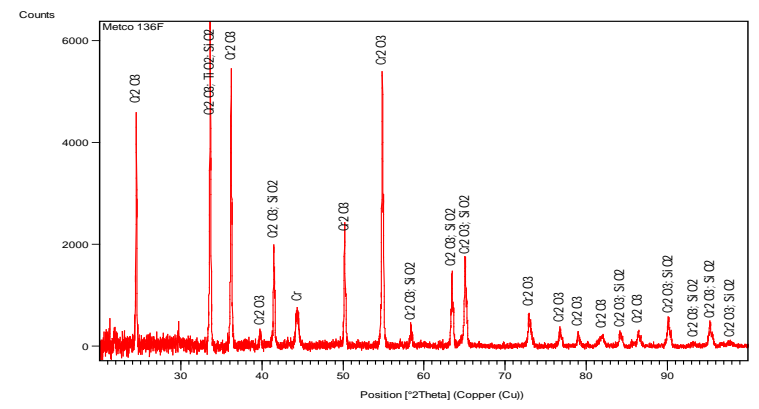

c)

Fig. 4. X-ray diffraction, diffraction interval: 2 theta $=20 \ldots 100^{\circ}$ : a) Metco 130,

b) Metco 81NS, c) Metco 136F.

\section{MICROINDENT Analysis}

In the Fig. 5 there are presented the variation curves of the penetration force relative to the indentation depth following the micro indentation test for each deposited powder. It can be noticed that the indentation depth for the METCO 136F has the most reduced values compared to the METCO 130 and METCO 81 NS. 
METCO 130 is the powder with maximum values for microhardness. The applied force value for the indentation was $9 \mathrm{~N}$ for each sample. Table 4 presents the obtained values for each of the 3 powders used following micro indentation.

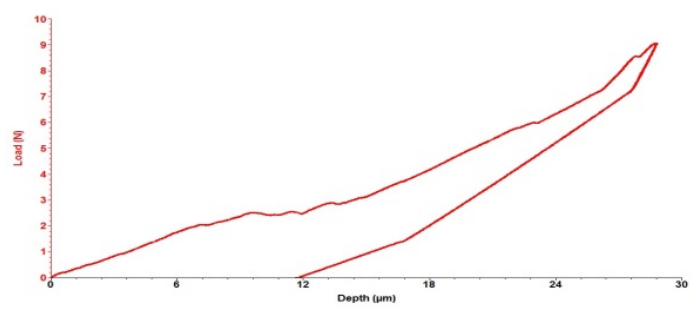

a)

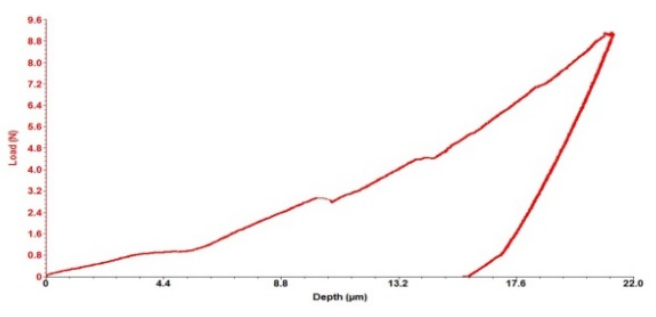

b)

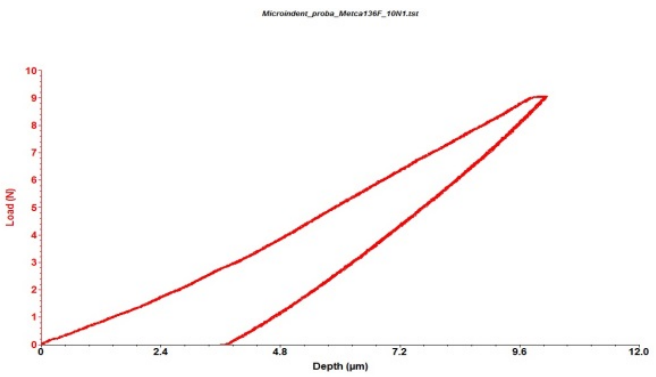

c)

Fig. 5. Variation curves of the penetration force relative to the indentation depth:

a) Metco 130, b) Metco 81NS, c) Metco 136F.

Table 4. Mechanical properties of coatings.

\begin{tabular}{|c|c|c|c|c|}
\hline Powder & $\begin{array}{l}\text { Microhardness } \\
\text { (GPa) }\end{array}$ & $\mathrm{COF}$ & Stiffness $(\mathrm{N} / \mu \mathrm{m})$ & $\begin{array}{l}\text { Young Modulus } \\
\text { (GPa) }\end{array}$ \\
\hline Metco 130 & 0.4728 & 0.58 & 0.5866 & 3.5586 \\
\hline $\begin{array}{l}\text { Metco } \\
81 \mathrm{NS}\end{array}$ & 0.5684 & 0.79 & 2.4043 & 16.1916 \\
\hline $\begin{array}{l}\text { Metco } \\
136 \mathrm{~F}\end{array}$ & 1.0573 & 0.44 & 1.6833 & 15.387 \\
\hline
\end{tabular}

The highest value of the apparent coefficient of friction is obtained for the Metco 81NS powder (Fig. 6). The Metco 136F coated products exhibit superior values of microhardness compared with other Metco 130 powders with the lowest value. 
Elastic modulus values for the three deposited powders range from 4 to $16 \mathrm{GPa}$, with Metco 130 having the lowest modulus of Young's 4 GPa module (Fig. 7). In Figs. 7 and 8 are represented comparatively the Young modulus parameters for the 3 deposited powders and respectively a comparative graph for the 3 used powders.
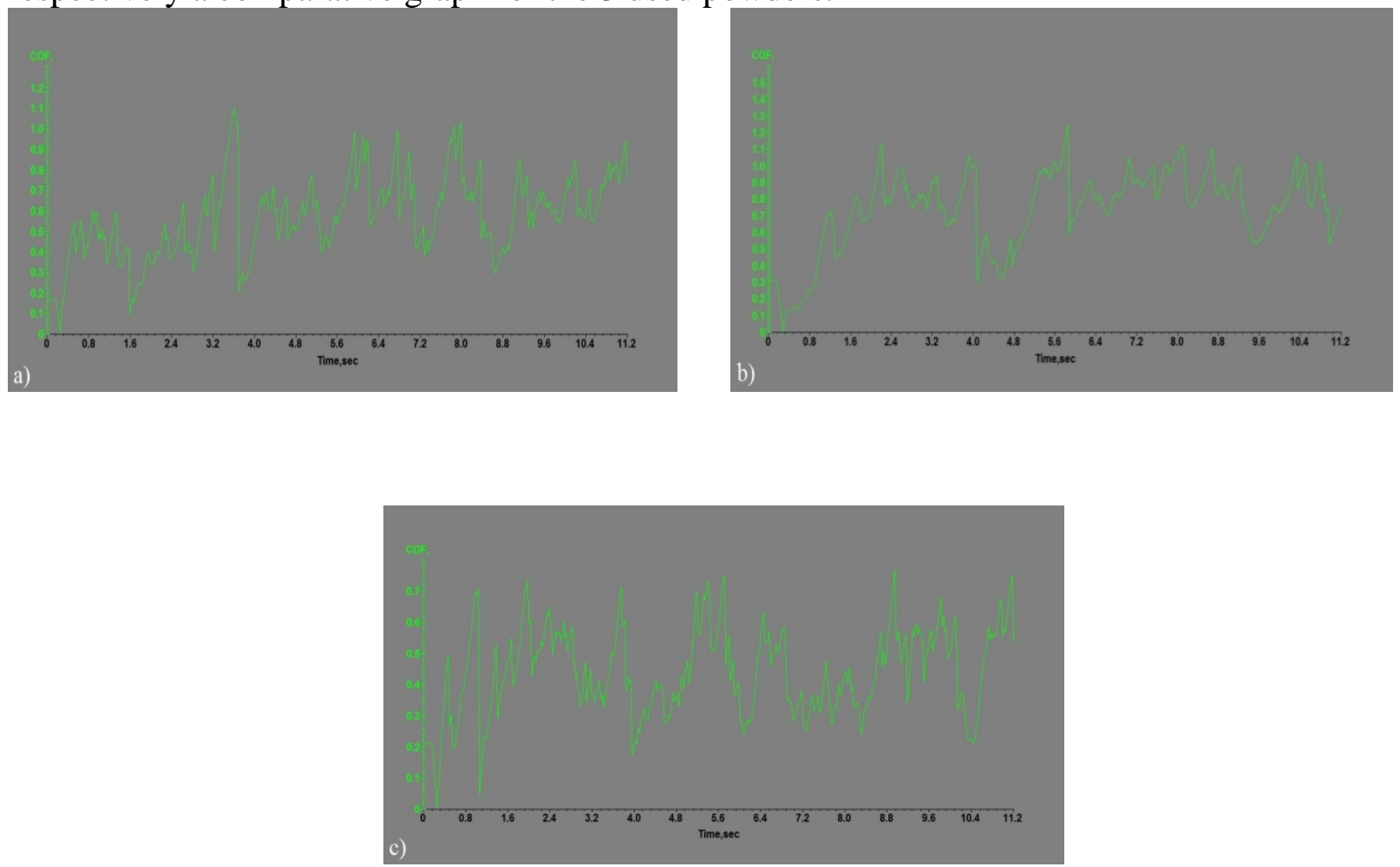

Fig. 6. Time variation diagram for apparent coefficient of friction : a) Metco 130;

b) Metco 81 NS, c) Metco 136 F.

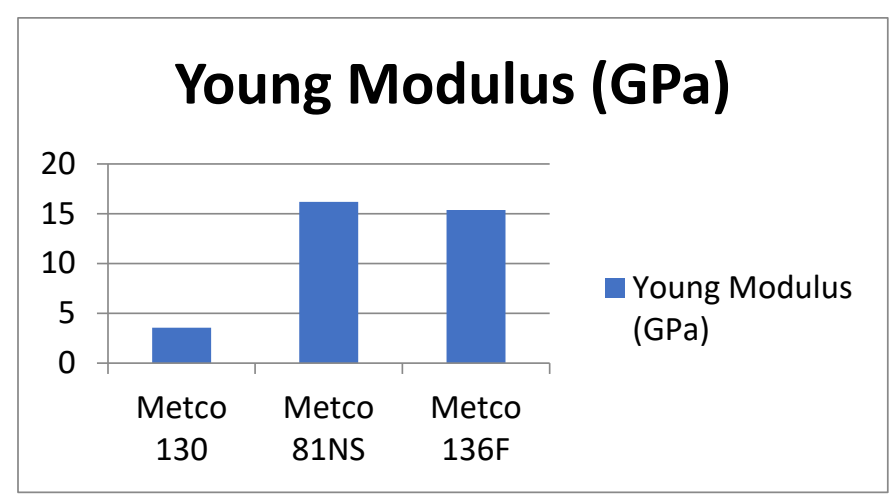

Fig. 7. Determination of the Young modulus parameters for the 3 deposited powders. 


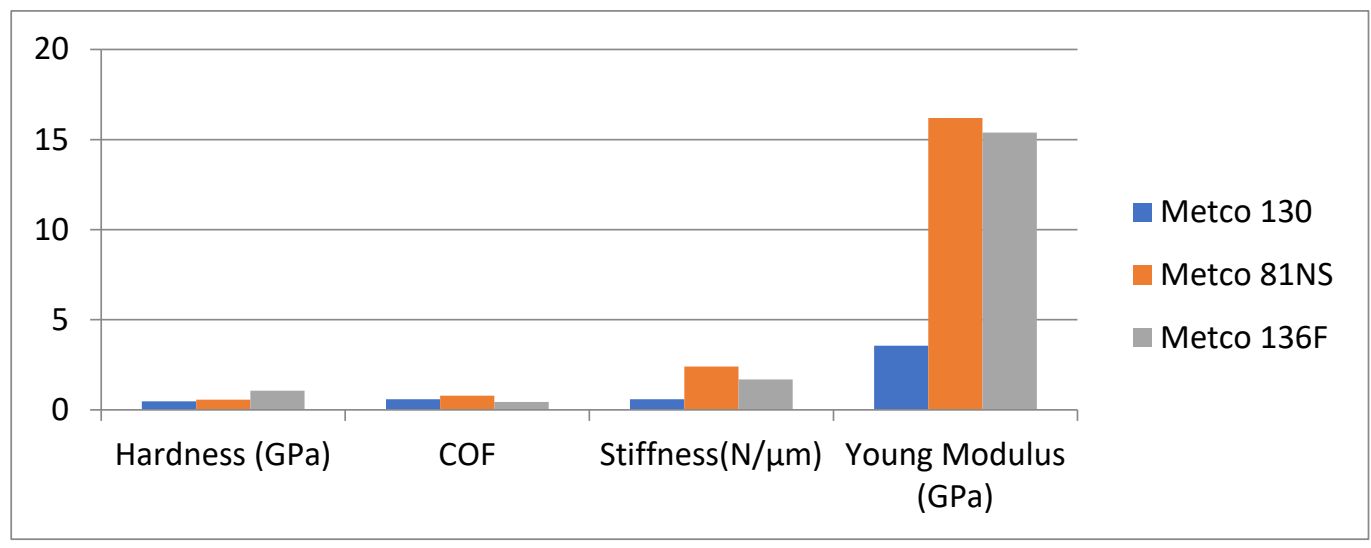

Fig. 8. Comparative graph for the 3 powders used with the obtained parameters following the micro scratch process.

\section{Summary}

Although all 3 powders have been developed for intensive wear environments, notable differences are revealed following deposited layers analysis. In the deposition process the same parameters were taken into consideration, but different layers had different thickness. Samples with METCO 130 layer had $306 \mu \mathrm{m}$ layer, METCO 81 NS had $107 \mu \mathrm{m}$ and METCO 136F had $110 \mu \mathrm{m}$. XRD Analysis revealed complex microstructural characteristics for all 3 powders. According to the microstructural analysis, the layers have been deposited uniformly, having low porosity and no major structural defects could be observed.

The highest value of the apparent coefficient of friction is obtained for the Metco 81NS powder and METCO 136F has the lowest value. The highest values for the Young modulus are obtained by METCO 81 NS powder, while METCO 136F has the highest microhardness values.

Micro scratch analysis revealed that the obtained layers had a good adhesion and do not require intermediate layer that would require increased expenses and more time for the deposition process. Plasma jet deposition would represent an interesting alternative for classic treatment solutions of the crankshaft.

\section{References}

[1] H. Hermann, S. Sampath, R. McCune, Thermal spray: current status and future trends, Thermal Spay Coatings 25 (2000) 17-25. https://doi.org/10.1557/mrs2000.119

[2] C. Paulin, D.L. Chicet, B. Istrate, M. Panţuru, C. Munteanu, Corrosion behavior aspects of Ni-base self-fluxing coatings, IOP Conference Series: Mater. Sci. Eng. 147 (2016), Article number 012347.

[3] C.A. Tugui, C. Nejneru, D.G. Galusca, M.C. Perju, M. Axinte, N. Cimpoesu, P. Vizureanu, The influence of the Al deposition by MOC-CVD method on stainless steel thermal conductivity depending on the substrate roughness, J Optoelectron. Adv. Mater. 17 (2015) 18551861.

[4] I. B. Roman, M.H. Tierean, J. L. Ocaña, Effects of laser shock processing on 316L stainless steel welds, J Optoelectron. Adv. Mater. 15 (2013) 121-124. 
[5] M.B. Beardsley, P.G. Happoldt, K.C. Kelley, Thermal barrier coatings for low emission, high efficiency diesel engine applications- SAE International 1999-01-2255.April 26-28, 1999.

[6] T. Bell, Y. Sun, A. Suhadi, Environmental and technical aspects of plasma nitrocarburizing, Vacuum 59 (2000) 14-23. https://doi.org/10.1016/S0042-207X(00)00250-5

[7] H. Liu, J.C. Li, F. Sun, J. Hu, Characterization and effect of pre-oxidation on D.C. plasma $\begin{array}{llllll}\text { nitriding for } & \text { AISI4140 steel, } & \text { Vacuum } & 109 & \text { (2014) 170-174. }\end{array}$ https://doi.org/10.1016/j.vacuum.2014.07.017

[8] J.R. Davis (Ed.), Surface hardening of steels: understanding the basics, ASM International, Materials Park, OH, 2002.

[9] F. Hakami, M.H. Sohi, J. R. Ghani, Duplex surface treatment of AISI 1045 steel via plasma nitriding of chromized layer, Thin solid Films 519 (2011) 6792-6796. https://doi.org/10.1016/j.tsf.2011.04.054

[10] Sh. Ahangarani, F. Mahboubi, A.R. Sabour, Effects of various nitriding parameters on active screen plasma nitriding behavior of a low-alloy steel, Vacuum 80 (2006) 1032. https://doi.org/10.1016/j.vacuum.2006.01.013

[11] A. Rahim, M. Sahaba, N. H. Saadb, S. Kasolangb, J. Saedonb, Impact of plasma spray variables parameters on mechanical and wear behaviour of plasma sprayed $\mathrm{Al}_{2} \mathrm{O}_{3} 3 \%$ wt $\mathrm{TiO}_{2}$ coating in abrasion and erosion application, Procedia Engineering 41 (2012) 1689-1695. https://doi.org/10.1016/j.proeng.2012.07.369

[12] W. Żórawski, A. Góral, O. Bokuvka, K. Berent, Microstructure and mechanical properties of plasma sprayed nanostructured and conventional Al2O3-13TiO2 coatings, Proceedings of the International Thermal Spray (ITSC) Conference. Busan, Republic of Korea, 2013.

[13] Kim G E, Thermal Sprayed, Nanostructured coatings: applications and developments, Perpetual Technologies, Inc., Ile des Soeurs, Quebec, Canada (2011) 91-92. 